\title{
RELEYENDO EL SURREALISMO DESDE UNA PERSPECTIVA FEMINISTA ${ }^{1}$
}

\section{REREADING SURREALISM FROM A FEMINIST PERSPECTIVE}

Author / Autora:

Marina Susana Cendán Caaveiro

Universidad de Vigo

Vigo, Spain.

scendan@uvigo.es

https://orcid.org/0000-0003-3642-2419

Submitted / Recibido: 01/11/2020

Accepted / Aceptado: 22/02/2021

To cite this article / Para citar este artículo: Cendán Caaveiro, M. S. (2022). Releyendo el surrealismo desde una perspectiva feminista. Feminismo/s, 39, 39-57. https://doi. org/10.14198/fem.2022.39.02

Licence / Licencia:

This work is licensed under a Creative Commons Attribution 4.0 International.

\section{(c) (i)}

(C) Marina Susana Cendán Caaveiro

\section{Marina Susana CENDÁN CAAVEIRO}

\section{Resumen}

El objetivo de este estudio es repensar el surrealismo, contextualizándolo en el presente y revisando críticamente algunos de sus postulados teóricos, particularmente aquellos que han incidido en la construcción de una imagen estereotipada de la mujer. Musas, niñas eternas o femme fatales, los surrealistas ejercieron a través de sus obras y escritos una manipulación continuada y, en muchos casos, intolerable del cuerpo e imagen de la mujer, bajo el pretexto del erotismo, la sexualidad o el mito. El surrealismo abrió sus puertas a más creadoras que ningún otro movimiento de vanguardia, sin embargo, su insistencia en el entendimiento de las mismas como sujetos poéticos, hizo que desaprovechase la oportunidad de revisar, objetivamente, las motivaciones femeninas. Basta observar las creaciones de muchas artistas surrealistas para apreciar que sus intereses no tienen nada que ver con los de sus colegas masculinos: pocas veces se identificaron con la mitología erótica o la simbología freudiana, construyendo un imaginario que ponía en valor sus propias

1. El presente texto se enmarca dentro de las líneas de investigación del grupo $d x 5$. Digital E Graphic Art Research (Universidad de Vigo). 
circunstancias personales. Como punto de partida metodológico, nos hemos servido de una publicación relativamente reciente (2005) de Alyce Mahon, Surrealismo, Eros y política (1938-1968), la cual reivindica la vigencia del surrealismo valiéndose de argumentos filosóficos, idealismos y mitos. Contrastando los puntos de vista de Mahon con las contribuciones de figuras clave del feminismo y estudiosas del surrealismo, aportamos una serie de reflexiones sobre las estructuras ocultas de poder, tratando de desenmascarar aquellos relatos que, tras una supuesta objetividad, manifiestan un continuismo ideológico con los mecanismos de poder tradicionales. Asimismo, planteamos la necesidad de permanecer vigilantes sobre las fuentes divulgativas y las metodologías docentes y académicas, en aras de contextualizar y analizar críticamente los excesos de determinadas ideologías artísticas

Palabras clave: Surrealismo; erotismo; patriarcado; feminismo; mujeres en el arte; estereotipos.

\begin{abstract}
The object of this study is to rethink surrealism, contextualizing it in the present and critically reviewing some of its theoretical postulates, particularly those that have influenced the construction of a stereotyped image of women. Muses, eternal girls or femme fatales, the surrealists exercised through their works and writings a continuous and, in many cases, intolerable manipulation of the body and image of women, under the pretext of eroticism, sexuality or myth. Surrealism opened its doors to more female creators than any other vanguard movement. However, its insistence on understanding them as poetic subjects meant that it missed the opportunity to review, objectively, female motivations. It is enough to observe the creations of many surrealist artists to appreciate that their interests have nothing to do with those of their male colleagues: they rarely identified with erotic mythology or Freudian symbolism, building an imaginary that put in value their own personal circumstances. As a methodological starting point, we have used a relatively recent publication (2005) by Alyce Mahon, Surrealism, Eros and Politics (1938-1968), which vindicates the validity of surrealism using philosophical arguments, idealisms and myths. Contrasting Mahon's views with the contributions of key figures in feminism and scholars of surrealism, we contribute a series of reflections on the hidden structures of power, trying to unmask those narratives that, behind a supposed objectivity, manifest an ideological continuity with traditional power mechanisms. Also, we propose the need to remain vigilant about the information sources and the teaching and academic methodologies, in order to contextualize and critically analyze the excesses of certain artistic ideologies.
\end{abstract}

Keywords: Surrealism; eroticism; patriarch; feminism; women in art; stereotypes.

Feminismo/s 39, January 2022, 39-57 


\section{INTRODUCCIÓN}

Iniciamos la presente introducción partiendo de una premisa que, no por manida, deja de estar vigente: lo personal continúa siendo político. Lo personal resultó un argumento motivador a la hora de afrontar la presente investigación porque sus contenidos manifiestan la urgencia personal de conciencia sobre la relectura de la historia del arte desde un punto de vista integrador y feminista.

La inmersión en la historia del arte de muchos docentes de mi generación, tanto en el instituto como en la carrera universitaria, se hizo obviando absolutamente la perspectiva de género. Algunos de los libros que nos sirvieron de referencia, la Historia del Arte de Gombrich ${ }^{2}$, por citar uno en concreto, no menciona a una sola mujer. Y en otros manuales -ciertamente encumbrados- el trabajo de las mujeres artistas se trataba de manera superficial y sesgada. Fue esa percepción parcial y miope de la historia del arte la que, desgraciadamente, nos sirvió de guía para la elaboración de nuestros primeros temarios docentes.

Replantear la docencia y divulgación de la historia del arte, dando cabida a la trayectoria de mujeres artistas largamente silenciadas, infravaloradas o tratadas como rarezas, no es tarea fácil. Y no lo es, porque no se trata de incluir aleatoriamente una serie de nombres femeninos en el selecto club de creadores masculinos, sino de integrar a las mujeres artistas de manera coherente en un contexto que refleje sus realidades personales, aspiraciones y contradicciones. $\mathrm{O}$ como bien manifiesta la escritora australiana Germaine Greer (2005), se trata de

mostrar a las mujeres no como una lista de individualidades destacadas, sino como miembros de un grupo que tiene mucho en común, atormentadas por diferentes conflictos de motivación y dificultades que, en la carrera para la realización y el éxito, son los obstáculos. (p. 6)

Con todo, el detonante concreto que alentó la redacción de este texto fue la revisión crítica de la bibliografía vinculada al surrealismo, la voluntad de emprender un análisis sobre cómo eran percibidas las mujeres artistas

2. Sobre esta circunstancia ha reflexionado certeramente la artista María Gimeno en la conferencia performativa Queridas Viejas Project, cuya visualización recomendamos (Gimeno, 2018). 
que orbitaban en torno al núcleo de poder que representaban Breton y sus acólitos, así como la necesidad de integrar y difundir los puntos de vista de las mismas en relación a contextos y situaciones específicas. No estamos hablando, únicamente, de insertar sus aportaciones en un discurso histórico y/o cronológico, sino de mostrar cómo estas han sido cosificadas y transformadas en un ente idealizado y abstracto. Cada una de las mujeres artistas que han estado vinculadas al surrealismo, bien por cuestiones de amistad, afinidad artística o relaciones personales, constituye un universo particular y diferenciado que exige lecturas individualizadas.

Resulta justo admitir la deuda intelectual de nuestras pesquisas con los análisis establecidos por Whitney Chadwick (1991, 1999, 2017), los cuales nos han permitido articular criterios comparativos rigurosos entre realidades divergentes (creadores/creadoras). Igualmente debemos citar las aportaciones de autoras clásicas del feminismo (Simone de Beauvoir, Kate Millet, Xaviére Gauthier, Germaine Greer, etc.) cuyas observaciones y relecturas nos han guiado a la hora de encarar críticamente nuestro argumentario.

No obstante, será una publicación relativamente reciente -del 2005, editada en español en 2009- de Alyce Mahon, Surrealismo, Eros y política (1938-1968), la que utilizaremos como punto de partida para repensar la narrativa, los referentes y objetivos del surrealismo. La mayoría de las creaciones surrealistas que cita Alyce Mahon en su libro nos resultan viejas conocidas, sin embargo, la profundización en la lectura y descodificación de los significados que les asigna la autora nos ha motivado a articular una serie de reflexiones encaradas desde la especificidad de los tiempos presentes.

En su texto -sin duda un trabajo de investigación encomiable- Alyce Mahon reivindica la preponderancia del surrealismo más allá de los años treinta, y lo hace analizando los principales hitos expositivos del movimiento: cuatro exposiciones realizadas entre los años 1938 y 1968, en las que Eros, el Dios griego del amor y el deseo, ocupa un lugar preponderante, impregnándolo todo de una sexualidad escandalosa, abyecta y, paradójicamente, romántica.

Lo que nos ha resultado más revelador del argumentario de Alyce Mahon es el «convencimiento» y la «neutralidad» con que la autora describe aquellos conceptos que no sólo originaron los diseños de las exposiciones surrealistas, sino muchas de las propuestas de los artistas participantes. No se vislumbra 
en su texto un cuestionamiento de la hegemonía masculina -por ejemplo, la presencia mayoritaria de hombres en las exposiciones colectivas o, y lo que es más importante, la ausencia de mujeres en los centros de poder, aquellos en los que se debatían y decidían las cuestiones importantes-, la caducidad ideológica de determinados referentes o la violencia que transmiten algunas obras cuya génesis nos hemos preocupado de revisar.

En buena parte de las creaciones artísticas que ilustran el libro de Alyce Mahon, abundan las imágenes de cuerpos femeninos desnudos, mutilados, prostituidos, supuestamente violados o denigrados, cuya «realidad» es excusada bajo el pretexto de conceptos filosóficos, mitos e idealismos varios. Estamos hablando de obras largamente estudiadas y posicionadas, en un lugar privilegiado, por colectivos artísticos e intelectuales.

Pero quizás el elemento que nos ha suscitado una mayor confusión en los análisis establecidos por Alyce Mahon es la demoledora actualidad de los mismos, dado que la fecha de publicación de su libro se remonta al año 2005. A pesar de que la igualdad entre hombres y mujeres continúa siendo una meta pendiente, la experiencia nos ha enseñado que, ni nuestros actos, y mucho menos los contenidos de una publicación sobre arte, pueden resultar inocentes. Todo es susceptible de crear y transmitir ideología. Consideramos que para avanzar en el conocimiento del arte -por muy «retóricamente» encumbrados que estén sus autores- es necesario reflexionar sobre las estructuras «ocultas» de poder a las que va aparejado, tratando de desenmascarar aquellos relatos que, tras una supuesta objetividad, manifiestan un continuismo ideológico con las estructuras de poder tradicionales.

Nuestro propósito, en definitiva, no es construir una barrera contra el surrealismo, sino más bien repensarlo y contextualizarlo en un presente, cuyo entendimiento pasa por la revisión crítica de sus argumentos, muchos de ellos elaborados en base a una manipulación excesiva y, en muchos casos, intolerable, del cuerpo de la mujer.

\section{2. ¿LA MUJER IDEAL? LA MUJER PASIVA}

Dada la imposibilidad de analizar todas las obras que formaron parte de las exposiciones organizadas por los surrealistas entre los años 1938 y 1968, nos centraremos en aquellas que manifiestan una obsesión palpable por el 
cuerpo de la mujer, así como una particular confluencia de referentes a partir de los cuales establecer análisis críticos. La primera obra objeto de estudio es una instalación bautizada como La Calle de los Maniquies, presente en la Exposición Internacional del Surrealismo, celebrada en la Galería Beaux-Arts de París en el año 1938.

La instalación estaba compuesta de «16 maniquíes de la noche vendiendo su mercancía, cada una vestida de manera fetichista por un artista surrealista» (Mahon, 2009, p. 45). Entre los artistas participantes en dicha intervención nos encontramos nombres muy relevantes del aparato surrealista -André Masson, Yves Tanguy, Marcel Duchamp, Oscar Domínguez, Max Ernst, Salvador Dalí, Man Ray, Joan Miró, etc.- y una única mujer, Sonia Mossé, lo cual nos proporciona una primera pista sobre la participación real de las mujeres en la puesta en escena surrealista, un dato clarividente al que Alyce Mahon presta escasa atención, a pesar de ser una circunstancia que se repetirá en todas las exposiciones que aparecen referenciadas en su texto.

La participación de las mujeres artistas en el surrealismo no sólo fue minoritaria en las exposiciones, sino también en el desarrollo de sus debates, manifiestos y textos teóricos, es decir, su ausencia brilla donde verdaderamente se «cocinaban» las cuestiones importantes. Resulta revelador que la única mujer participante en La Calle de los Maniquies, Sonia Mossé, a pesar de contar con una amplia trayectoria creativa -como pintora, diseñadora gráfica, escultora, decoradora o bailarina- o incluso de haber ejercido el correspondiente papel de musa, sea una auténtica desconocida, o que su presencia en los anales de la historia del arte sea prácticamente nula, cuando no inexistente.

Creemos significativo señalar que las intervenciones que los artistas surrealistas realizaron sobre los maniquíes va más allá del culto al «fetichismo de consumo» al que alude Alyce Mahon (2009) en su libro: «como objeto utilizado para exhibir la cultura consumista, el maniquí ofrecía un medio simbólico de abordar el oropel del fetichismo de consumo, con su cuerpo delgado, su rostro perfecto y sus manos y pies delicados» (p. 45). Bajo el recurso de lo simbólico subyacen representaciones de mujeres desnudas, desmembradas y sometidas a todo tipo de excesos y banalizaciones. Se presupone que estamos ante un gran burdel en el que las prostitutas son 
susceptibles de alimentar el poder subversivo de Eros, la gasolina que estimula la mayoría de los impulsos creativos del genio surrealista.

Si hacemos caso de las afirmaciones de Xaviére Gauthier (1976) en su emblemático estudio Surrealismo y Sexualidad:

La prostitución es una profesión alienada como cualquier trabajo que, no considerándose que deba provocar placer y careciendo en sí de sentido, sólo se realiza a cambio de un salario. Pero la explotación de la prostituta se efectúa en dos planos que se sobreañaden el uno al otro: por una parte, como trabajadora; por la otra, como mujer. Éste último aspecto no puede ser subestimado: nunca una prostituta trabaja para sí; siempre está bajo el dominio de un hombre que a la vez la protege y la explota. (p. 123)

Resulta difícil abstraerse de los principios de dominio-poder sobre los que se han cimentado las bases del patriarcado, señalados por Gauthier. El factor revolucionario y subversivo que sustenta la abundante artillería retórica surrealista, refrendada por Alyce Mahon en su libro, nos genera nuevos interrogantes: ¿qué pueden representar los maniquíes más allá de la cosificación de la mujer? La respuesta que más nos convence es aquella que revela la construcción de una imagen pasiva, manipulable e impotente, dispuesta a satisfacer los placeres y el imaginario de un colectivo artístico forjado a partir de una ignorancia premeditada de las necesidades de las mujeres reales.

Continuando con la descripción de la Exposición Surrealista del 38, Alyce Mahon (2009) concluye con una declaración de la que nos interesa señalar su frase final: «la exposición introduce al espectador en una visión del mundo profana y surrealista mediante la transformación de la moderna galería (de cubo blanco) en un espacio oscuro, cálido y húmedo que apestaba a lo abyecto femenino» (p. 20). Según la autora, «puede argumentarse que la disposición misma de la exposición surrealista de 1938 era en sí una representación del sexo femenino en términos espaciales» (p. 49). Efectivamente, Mahon está introduciendo otro de los argumentarios clave del surrealismo, el cual, alentado por las teorías psicoanalíticas de Sigmund Freud, -convenientemente adaptadas a sus circunstancias- fue utilizado para profundizar en la construcción de una imagen estereotipada de la mujer.

La mujer obsesionaría a Freud desde el primer momento, entendiéndola de manera ambivalente: como enigma y como problema. Según Freud, la mujer distrae al hombre, alejándolo de sus tareas intelectuales. La 
correspondencia que Freud mantiene con su mujer nos proporciona clarividentes pistas sobre su verdadera personalidad: «espera un poco, cuando yo llegue, te acostumbrarás a tener un nuevo dueño, y un dueño severo, es cierto, pero no encontrarás otro que te ame tanto y se preocupe más en lo que se refiere a ti» (Assoun, 1994, p. 47).

Según Freud, la mujer necesita un dueño para sentirse realizada, estableciendo con ella una relación de dominación que la sitúa en una situación de inferioridad. Dicha situación se fundamenta, entre otras circunstancias, en la «ausencia de pene»-símbolo de superioridad masculina en la cultura patriarcal y fuente de orgullo desmesurado (Millet, 1995)-, lo cual la mantiene en un estado de castración y envidia permanente: la envidia del pene. Resulta inaudito que tal argumento se hubiese transformado en una consigna que los seguidores de Freud seguirían al pie de la letra, transmitiendo y perpetuando una consideración de la mujer como «algo esencialmente orgánico, es decir, equiparable con la constitución biológica de la hembra, sin tener en cuenta las circunstancias sociales que rodean a la mujer» (Millet, 1995, p. 344).

Afortunadamente, en los años setenta del siglo XX surgen nuevos enfoques en el ámbito del feminismo que retoman las teorías psicoanalíticas de Freud, analizándolas críticamente y extrayendo vehementes conclusiones que desmontan las consideraciones del psicoanalista, empeñado en confinar a las mujeres en un espacio de subordinación patriarcal. Entre los ensayos fundamentales, conviene recordar uno, Política sexual de Kate Millet (1995), en el cual la autora expresa sin ambages su opinión sobre las argumentaciones freudianas, afirmando que «las niñas no envidian el pene, sino las prerrogativas sociales a las que éste da derecho» (p. 334).

Entendemos que en una exposición en la que la provocación constituye uno de sus principales leitmotiv, no podía faltar uno de los artistas que más a gusto se ha movido en aguas turbulentas: Marcel Duchamp, presente con un maniquí que representaba su alter ego, Rrose Sélavy, la cual abandona el aspecto de burguesa respetable para, supuestamente, transformarse en exponente de la doble identidad que tanto fascinaba al autor.

La presunta ambigüedad sexual de Rrose venía dada, básicamente, por la indumentaria masculina con la que Duchamp «disfraza» a su maniquí: sombrero, chaleco, corbata, chaqueta y zapatos. El artista se aseguró de 
completar la puesta en escena con un detalle convenientemente perverso, desnudando a Rrose de cintura para abajo, lo cual dejaba su pubis al descubierto, castigándola a una situación de clara desprotección.

No era la primera vez que el artista dejaba constancia de su obsesión por los pubis femeninos. En gran parte de la iconografía duchampiana las mujeres aparecen representadas de manera jocosa, como chistes facilones o picantes: como viudas frescas (Fresh Widow); desmembradas y sin identidad (Étant-Donnés); como solteronas que merecen serlo (¿Por qué no estornudar, Rrose Sélavy?); con bigote y el culo caliente (LHOOQ); o como extrañas maquinarias tituladas crípticamente (La novia desnudada por los solteros).

Desnudar a Rrose de cintura para abajo no supone ningún acto radical. Alyce Mahon (2009) justifica la intervención de Duchamp argumentando que el artista «contribuyó a la «perturbación» de los tradicionales roles de género por los surrealistas y a su adopción de lo femenino» (p. 20). Sin embargo, el objetivo bien podría haber sido otro: no sólo alterar los roles de género, sino, y como señaló hace décadas Xáviere Gauthier (1976), mezclarlos: «de la misma manera que otros surrealistas, frente a la sexualidad, Duchamp se espanta, se repliega y defiende» (p. 184).

\section{LA MUJER NIÑA}

La celebración de la fuerza subversiva de Eros continuó ocupando un lugar primordial en las tácticas revolucionarias de los surrealistas. El abanico erótico se iría ampliando con el mantenimiento de antiguos referentes y la incorporación de otros con los que legitimar el poder del erotismo como elemento de transformación política y social. Sin embargo, la lucha revolucionaria en el surrealismo tuvo un carácter unilateral, su punto de vista fue exclusivamente masculino, lo cual explica el alto grado de subjetivación al que fue sometido el cuerpo de la mujer, el cual fue sublimado, apaleado o manipulado de mil maneras diferentes en pos del progreso y la civilización.

Entre las incorporaciones de carácter erótico-subversivo destacaremos una, el Marqués de Sade, el cual inflamó la imaginación surrealista hasta límites insospechados, jugando un papel determinante en la configuración de narrativas y experimentaciones artísticas. Según Angela Carter (1979), la sexualidad pornográfica y abyecta, al margen de todo convencionalismo, 
difundida por Sade en los albores del siglo XIX, le concedió a la mujer un papel sexualmente activo: en sus relatos literarios la mujer agrede en la misma medida que es agredida (p. 37). Una mujer capaz de las más atroces perversiones -pensemos en el personaje de Eugène de Mistival, creado por Sade (1795) en la Filosofía del Tocador, la cual no duda en someter a su propia madre a todo tipo de vejaciones (p. 132) - y, sobre todo, ajena al ideal femenino-burgués de la época, en tanto que mujer abnegada, madre y esposa ejemplar.

El imaginario sadiano es el combustible que alimentará las expectativas de un artista surrealista sobre cuyo trabajo nos gustaría reflexionar. Nos estamos refiriendo a Hans Bellmer, un alemán que consiguió fascinar al pope Breton con sus perturbadoras fotografías de muñecas, incorporándolo al movimiento y apoyándolo con una gran fidelidad, tanto en sus escritos como en las exposiciones del grupo. Las muñecas de niñas con cuerpos desmembrados de Bellmer, casi siempre sin una identidad reconocible y vestidas con complementos fetichistas -medias, lazos, bailarinas, pelucas, etc.- que incrementaban la apariencia perturbadora de las mismas, recogen las perversiones y fantasías sexuales del propio autor, el cual, estimulado por las lecturas de Sade, compone un universo basado en ataques continuados al cuerpo de la mujer-niña.

La imaginería escabrosa de Bellmer no se limitó al universo infantil, el artista utilizó a su pareja, la creadora alemana Unica Zürn, como víctima sadiana, representándola en una estremecedora serie de fotografías en las que aparece envuelta y aprisionada por unas cuerdas que comprimen su cuerpo desnudo, convirtiéndolo en un amasijo de formas grotescas sin identidad. La gran paradoja es que Unica Zürn resultaría más conocida por estas fotografías sin rostro que por su propio trabajo artístico y literario; o que su vida estuvo condicionada por frecuentes crisis psiquiátricas que concluirían con un trágico suicidio en el año setenta.

En un texto clave para entender en profundidad las conexiones entre deseo y violencia en el imaginario surrealista, Juan Vicente Aliaga plantea la siguiente cuestión: « ¿Es posible pasar del deseo a la violencia?» (2007, p. 121). Como a aquel, el análisis de las obras de Bellmer desde una óptica contemporánea nos suscita multitud de interrogantes: ¿cómo debemos interpretar dichas creaciones? Antes de emitir un veredicto, consideremos las 
opiniones de Alyce Mahon, la cual justifica la agresividad de las muñecas de Bellmer amparándose en el contexto, en las presiones que el alemán sufrió por parte de su padre para unirse a la causa nazi y al descontento con la situación de crisis social y económica que asolaba Europa.

Si la iconografía nazi enfatizaba el confort de lo femenino maternal, moral y natural -aplicando el diktat del Tercer Reich para las mujeres: Kinder, Kirche, Küche (hijos, Iglesia, cocina)-, la muñeca de Bellmer enfatizaba el poder siniestro y la amenaza de lo femenino. La explicación del propio Bellmer sobre la muñeca se dirigía a la relación entre el cuerpo erótico y el cuerpo político, unión que permitiría mirar el mundo con ojos nuevos (Mahon, 2009, p. 30).

¿Realmente -como señala Mahon- consiguió Bellmer transformar la mirada del espectador? El paso del tiempo y los análisis realizados desde postulados feministas nos sugieren todo lo contrario. Así, Whitney Chadwick (1999) argumenta lo siguiente: «la sexualización de la creatividad, el mito vanguardista de liberación individual construido a partir de la desigualdad sexual y social redujo a mera carne el sujeto femenino, el cual se representa impotente ante el artista-espectador» (p. 280). Efectivamente, el papel que juega la mujer en el conjunto de las representaciones de Bellmer es la de un sujeto pasivo y anulado, cuya imagen es pervertida al extremo. Obviamente, -y como reitera Chadwick-, parece que «la liberación del artista significa el dominio de otros» (p. 5).

De las acusaciones sobre la ausencia de objetividad, o la parcialidad en los análisis de los trabajos de Bellmer, tampoco se librarían teóricas de prestigio como Rosalind Krauss, la cual en su texto sobre fotografía titulado, L'amour Fou: Photography and Surrealism, se niega a ver los cuerpos atacados de las muñecas de Bellmer como cuerpos femeninos (Caws et al., 1991, p. 20), silenciando la violencia contra las mujeres en pos de la construcción de nuevos enfoques críticos apoyados en los viejos temores a la castración de Freud o en las teorías de Bataille, examinando las muñecas desde una perspectiva masculina. Según Kuenzli (1991), los análisis de Krauss representan un indicio de cómo una buena parte de la teoría moderna permanece atrapada en las fantasías masculinas surrealistas, apoyadas en las teorías misóginas de Freud. 
En el texto titulado La novia frente a los solteros, Patricia Mayayo disecciona el relato introductorio de Rosalind Krauss en Bachelord, en realidad una recopilación de artículos sobre reconocidas artistas entre las que figuraban Louise Bourgeois, Agnes Martin, Eva Hesse, Cindy Sherman, Francesca Woodman, Sherrie Levine y Louise Lawler. Titulada Claude Cahun and Dora Maar: By Way of Introduction, la introducción contradice, según Mayayo (2000),

la visión misógina del surrealismo en el mundo anglosajón, considerándolo un tópico reduccionista [...] El empeño de Krauss en obviar el problema de la subjetividad de género del/la creador/a invalida, en realidad, su propio proyecto: si el sexo del/la autor/a es irrelevante desde el punto de vista crítico, ¿qué sentido tiene, entonces, dedicar un volumen a analizar la obra de mujeres artistas (p. 8).

La representación de la mujer-niña en el imaginario surrealista adopta en otros creadores un perfil menos escabroso. El mito de la mujer niña, ingenua y pura, ocuparía los escritos de André Breton, Paul Éluard, Louis Aragon o Salvador Dalí, los cuales la consideraban un médium para adentrarse en los dominios del inconsciente. La transformación de la mujer en un símbolo, en una idea, fue uno de los desencadenantes de que una buena parte de las artistas próximas al surrealismo acabaran por desentenderse de un movimiento incapaz de comprender sus necesidades reales: sus ansias de progresar artísticamente como seres autónomos, su papel como madres -la maternidad contradecía la imagen mitificada de la mujer-niña- o la posibilidad de madurar sin ser sojuzgadas. Son precisamente dichas contradicciones las que explican que muchas de estas artistas desarrollasen su obra más personal al margen del movimiento surrealista.

Si rastreamos otros referentes asumidos por los surrealistas para construir su imaginario subversivo, algunos resultan, desde el punto de vista biográfico de sus protagonistas, perturbadores. Las ambiguas fotografías de Alice Lidell -la niña real que inspiró el personaje de Alicia en el país de las maravillas, cuya lectura ha contribuido a ensanchar nuestro mundo de fantasía- sitúan a Lewis Carroll en un territorio complejo que ha originado elocuentes dudas sobre sus verdaderas motivaciones morales.

Como quiera que sea, estamos hablando de niñas, es decir, de seres manipulables de los cuales resulta fácil abusar. De nuevo Xaviére Gauthier 
(1976) lo expresa alto y claro: «querer que la mujer siga siendo niña es querer que la mujer permanezca dependiente. Es la muñeca de salón que se mete en un fanal por miedo a que se rompa» (p. 55). ¿Cómo es posible no percibir semejante realidad? Las deliberaciones de Gauthier no sólo mantienen viva su vigencia, sino que nos advierten sobre la necesidad de permanecer alerta, a pesar de haber transcurrido casi cincuenta años desde la publicación de su ensayo sobre surrealismo y sexualidad.

\section{MUSAS SIN MUSOS}

En The Militant Muse, otro trabajo de investigación notable de Whitney Chadwick en el que se incluyen documentos inéditos, entrevistas, correspondencia personal y numerosos dibujos de mujeres artistas vinculadas al surrealismo, la autora explora no solamente el papel restrictivo de la musa, sino que pone en valor las relaciones personales entre artistas extraordinarias (Leonor Fini y Leonora Carrington; Claude Cahun y Suzanne Malherbe; Lee Miller y Valentine Penrose; Valentine Penrose y Alice Mahon; Frida Kahlo y Jacqueline Lamba Breton) cuyos vínculos de amistad contribuyeron a forjar su carácter como creadoras poderosas e independientes.

Resulta indudable que André Breton permitió la entrada en el grupo a más mujeres que ningún otro movimiento de vanguardia. Sin embargo su insistencia en la idealización, en el entendimiento de las mujeres como sujetos fundamentalmente poéticos, hizo que el surrealismo desaprovechase la oportunidad de revisar de forma objetiva las motivaciones femeninas. Atrapadas en su papel de musas, las mujeres artistas o aquellas que formaban parte de las creaciones surrealistas, raramente concordaban con las exigencias de un contexto en el que la explosión de dos contiendas mundiales había reconfigurado el perfil económico, político y social de Europa, incorporando a miles de mujeres al mercado de trabajo, las cuales comienzan a saborear las mieles de la independencia económica.

Paralelamente, las musas surrealistas surgen en un mundo en el que las mujeres de carne y hueso no podían votar (el voto en Francia se generalizó a partir del año 1945), circunstancia que debería resultar lo suficientemente elocuente para revisar el papel real que desempeñaban estas en el seno de la sociedad francesa. No apreciamos, sin embargo, una inquietud manifiesta en 
relación a lo dicho en los escritos u obras de las artistas surrealistas, muchas de las cuales acabarán refugiándose en una imaginería impregnada de magia, fantasía o en su propia realidad personal.

La relación de las artistas surrealistas con los miembros del grupo, ya fuesen creativas, de amistad o de carácter sentimental, acabarían condicionando la trayectoria y el reconocimiento de muchas de ellas. Así, Leonora Carrington le confiesa a Whitney Chadwick su enorme frustración cuando esta le pregunta por su relación con Max Ernst, respondiendo: «¡Solo fueron tres años de mi vida! ¿Por qué nadie me pregunta otra cosa?» (Chadwick, 2017, p. 126). En The Militant muse, Whitney Chadwick (2017) revela las sintomáticas confesiones que le hizo Roland Penrose sobre la que fue su pareja durante largo tiempo, la artista norteamericana Lee Miller, recriminándole: «no deberías escribir un libro sobre las mujeres. Ellas no fueron artistas» (p. 9).

Chadwick (2017) nos recuerda que Lee Miller continuaba siendo una gran desconocida en los años ochenta, y las noticias que se publicaban sobre ella solían guardar relación con su papel de amante de Man Ray, o como modelo y musa de los surrealistas (p. 10). Y ello a pesar de que la artista había desarrollado una carrera como fotógrafa experimental, o que ejerció de intrépida reportera de guerra, legándonos una serie de inquietantes y bellísimas fotografías, fruto de una experiencia profesional y personal que acabaría dejando una huella indeleble en su salud mental y física.

Muchas de las mujeres artistas próximas al círculo de Breton consideraban que el reconocimiento que este les profesaba resultaba insuficiente. Entre sus más vehementes detractoras debemos citar a Frida Kahlo, la cual encontraba las teorías de Breton «pretenciosas y aburridas» (Chadwick, 1991, p. 87). Kahlo era perfectamente consciente que el interés de Breton respecto a ella guardaba más relación con su condición «exótica», que con su capacidad como creadora de una imaginería personal, rebosante de connotaciones biográficas, culturales y antropológicas, que acabarían convirtiéndola en un fenómeno de masas.

Otra de las artistas que ejercería de musa surrealista fue Meret Oppenheim, la cual merece una consideración especial por sus particulares contribuciones al entendimiento del grupo. Oppenheim fue la autora de una obra emblemática del surrealismo, Juego de desayuno en piel, en realidad un 
ready made cuya adquisición por parte del MoMa (1936) la convertiría en una artista de culto.

Recientes investigaciones sobre la verdadera intención de la pieza evidencian las contradictorias relaciones que la artista mantenía con Breton, al cual acusa de re-significar algunas de sus creaciones (Caws et al., 1991, p.51). Según Meret Oppenheim, su interés no iba más allá de hacer realidad una conversación de café mantenida con Picasso, en la que reflexionaban sobre las connotaciones extrañas de un objeto cotidiano forrado con un material inusual como la piel, el mismo que la artista estaba utilizando para elaborar sus joyas para la prestigiosa firma de moda que Elsa Schiaparelli regentaba en la Plaza Vendôme de París. Fascinado con la pieza, Breton revierte el significado de la misma, transformándola en una metáfora de los genitales femeninos, el miedo a la castración y el fetichismo.

No obstante, será otra creación de Meret Oppenheim la que centre nuestro interés: se trata de una instalación que la artista realizó para la Exposición Surrealista de 1959, titulada Banquete caníbal. La temática de la exposición giraba de nuevo en torno al erotismo, de tal forma que el diseño de la misma estaba pensado para que los espectadores se sintiesen dentro de un enorme útero que, en palabras de Alyce Mahon (2009), se «burlaba de la naturaleza de doble filo del deseo erótico femenino: como algo incitador y amenazador al mismo tiempo» (p. 160). Situada al final del recorrido expositivo, la instalación de Oppenheim consistía en una mujer desnuda, pintada en tonos dorados y decorada con flores, la cual yacía inmóvil sobre una mesa cubierta con un mantel. Sobre su cuerpo desnudo se situaban los alimentos que los comensales, convenientemente vestidos, se disponían a ingerir.

Sobre las repercusiones de la instalación, Belton (1991) sostiene que Meret Oppenheim dudó sobre si esta sería correctamente interpretada, esto es, como la celebración de un festival de primavera, y no como lo que la pieza parecía ser: una mujer real postrada para consumo del placer masculino. La artista acusa nuevamente a Breton de trastocar la intención original de la pieza, impregnándola de connotaciones eróticas.

«Siempre hay una brecha entre los objetivos y la comprensión del público» (Caws et al., 1991, p.70) confiesa lacónicamente Meret Oppenheim a su entrevistador. Una declaración que nos genera nuevas dudas y consideraciones. En el momento de la presentación de la instalación había transcurrido tiempo 
suficiente desde que la artista iniciara su vínculo con los surrealistas, de ahí que -y desde la admiración que le profesamos- se eche en falta un argumento sólido que nos ayude a clarificar una propuesta cuya intención parecía la de «canibalizar» el cuerpo de la mujer.

En su esclarecedor estudio, Women Artists and the Surrealism, Whitney Chadwick (1991) explica que Meret Oppenheim fue una de las pocas artistas que le impidió reproducir sus obras, arguyendo que el «centralismo masculino» era una cuestión del siglo XIX, o que el movimiento surrealista había aceptado a artistas y escritoras en sus filas de manera desprejuiciada. Desde nuestro punto de vista, la cuestión no es si el surrealismo aceptó o no a mujeres artistas en sus filas, lo cual es un hecho estadísticamente constatable, sino cuál era el verdadero «poder» de estas en el seno del movimiento. En este sentido las conclusiones son rotundas: la presencia de mujeres en el surrealismo no solo fue minoritaria, sino que su realidad fue mistificada y sus logros artísticos silenciados en sus escritos y manifiestos teóricos.

En otras declaraciones Meret Oppenheim justifica su postura diciendo que «no hay un arte masculino o femenino» (Caws et al., 1991, p. 48), amparándose en que el sexo no juega un papel decisivo en el arte. Sin embargo, si en algún movimiento artístico el sexo desempeñó un papel fundamental fue en el surrealismo. Los surrealistas se encargaron de hacérnoslo saber reiteradamente: ironizando, teorizando, especulando, divirtiéndose incluso, con la manipulación del cuerpo e imagen de la mujer, la cual transformaron en «alteridad». La suya fue una visión unilateral que dejó fuera de juego a las mujeres.

Basta observar las creaciones de muchas mujeres surrealistas para darse cuenta de que sus intereses no tienen nada que ver con los de sus colegas masculinos: pocas veces se identificaron con la mitología erótica o la simbología freudiana, construyendo un imaginario que ponía en valor sus propias circunstancias personales. Es el caso de Leonora Carrington, Toyen, Dorothea Tanning, Remedios Varo, Frida Kahlo, Eileen Agar, Ithell Colquhoun, Leonor Fini y un largo etcétera de artistas que, a pesar de las dificultades para que se reconociese su talento, no dejaron de cultivar su individualidad y autonomía. Transformadas en mitos, las artistas surrealistas lucharon por desentenderse de la imagen estereotipada y arquetípica que les habían asignado. Su condición de mujeres reales concuerda con las lúcidas 
observaciones de Simone de Beauvoir en su obra paradigmática, El Segundo Sexo, a propósito de las creaciones poéticas de André Breton: «el mito de la mujer desempeñó un papel considerable en la literatura de Breton, pero ¿qué importancia tiene este en la vida cotidiana?»(Beauvoir, 1999, p. 351).

\section{CONCLUSIÓN: SE RUEGA «NO» TOCAR}

Concluimos sugiriendo que una de las reflexiones que es posible extraer de este texto abunda en la necesidad de permanecer vigilantes sobre las fuentes divulgativas y las metodologías docentes y académicas, tratando de contextualizar y analizar críticamente los «excesos» de determinadas ideologías artísticas fundamentadas en una visión negativa y estereotipada del cuerpo y de la imagen de la mujer.

En la conclusión de su libro, Alyce Mahon realiza una defensa enérgica de la vigencia del surrealismo y su supuesta utilidad social, afirmando que «Todavía no puede tocarse la campana por la muerte del surrealismo, ni se puede negar su poder de perturbar al mundo consciente» (Mahon, 2009, p. 227). Sus pronósticos chocan frontalmente con el veredicto emitido por Xaviére Gauthier cincuenta años antes, en el que sentencia al surrealismo como un movimiento fracasado en sus búsquedas revolucionarias a través del erotismo, el mito y la sexualización del cuerpo femenino. Según Gauthier (1976), «el vicio del idealismo surrealista se oponía a todo intento revolucionario. La idea de revolución no era más que una idea, sin la más mínima eficacia. Aquí se inscribe el fracaso del surrealismo, pues, si no era real, ¿para qué servía?» (p. 185).

Ciertamente supone una responsabilidad repensar la verdadera dimensión de las mujeres en la historia del arte, tratando de comprender sus vidas y motivaciones para generar alternativas que combatan los argumentos miopes. La realidad de las cifras nos alerta sobre la importancia de no bajar la guardia: si observamos la programación de muchos museos punteros, la presencia de mujeres, tanto en sus programaciones temporales, como en las colecciones permanentes, continúa dibujando un panorama desigual. En la mayoría de las facultades de Bellas Artes de nuestro país, el 80\% del estudiantado son mujeres, una estadística que se diluye con su incorporación al mundo profesional, en donde claramente los hombres resultan privilegiados. 
El peso de las responsabilidades maternales, familiares y domésticas hace que muchas mujeres se pierdan por el camino, frustrando sus posibilidades de crecimiento artístico y profesional.

Con todo, la realidad de las mujeres artistas en la actualidad no puede equipararse a las de las mujeres surrealistas, las cuales partían de una situación de «tutorización» permanente, o como acertadamente manifiesta Germaine Greer, de «egos dañados, de voluntades débiles, de libidos reprimidos y energías desviadas en neurosis» (2005, p. 337).

Finalizamos citando un pasaje del libro de Alyce Mahon a propósito del diseño que Marcel Duchamp realizó, en colaboración con Enrico Donati, para el catálogo de la Exposición Surrealista de 1947: un libro de artista cuya portada fue decorada con un pecho de gomaespuma, acompañado de un texto en el que se podía leer Prîere de toucher, es decir, se ruega tocar. Una entusiasta Mahon (2009) justifica la provocación duchampiana diciendo lo siguiente:

Dada la dimensión erótica del catálogo -un pecho que literalmente se podía cubrir con la palma de la mano para poder sujetar el libro- esa subversión asumió un aspecto maravillosamente cómico, permitiendo al espectador recrear un «doble tabú» (tocar y tocar lo prohibido, por así decirlo). (p. 143)

Quizás debamos puntualizar que la exposición se celebró en un contexto aun dramático: la Segunda Guerra Mundial acababa de finalizar y sus heridas estaban lejos de cicatrizar, lo cual explica el poco entusiasmo con que la crítica francesa recibió las ansias festivas del surrealismo, la mayoría de cuyos miembros habían pasado la contienda exiliados en Méjico y Estados Unidos.

La fascinación «maravillosamente cómica» a la que alude Mahon (2009) contrasta con la sórdida realidad que describe David Hare en una carta a Enrico Donati a propósito de la incapacidad de la sociedad francesa de aplaudir las provocaciones irreverentes del surrealismo: «Nos gusta tenerlo de vuelta porque nos pertenece, pero ¿cómo puede esperarse de nosotros, después de todo lo que hemos pasado durante la guerra, que nos lo tomemos en serio?» (Mahon, 2009, p. 145). 


\section{REFERENCIAS BIBLIOGRÁFICAS}

Aliaga, J. V. (2007). Orden fálico. Androcentrismo y violencia de género en las prácticas artísticas del siglo XX. Akal.

Assoun, P. L. (1994). Freud y la mujer. Nueva visión.

Beauvoir, S. (1999). El segundo sexo. Los hechos y los mitos. Cátedra.

Belton, R. J. (1991). Androgyny: Interview with Meret Oppenheim. En M. A. Caws, R. E. Kuenzli y G. Raaberg (Eds.), Surrealism and Women (pp. 17-26). The MIT Press.

Carter, A. (1979). La mujer sadiana. Edhasa.

Caws, M. A., Kuenzli, R. E.y Raaberg, G. (Eds.). (1991). Surrealism and Women. The MIT Press.

Chadwick, W. (1991). Women Artists and the Surrealist Movement. Thame and Hudson.

Chadwick, W. (1999). Mujer, arte y sociedad. Ediciones Destino.

Chadwick, W. (2017). The militant Muse: Love, War and the Women of Surrealism. Thames and Hudson.

Gauthier, X. (1976). Surrealismo y sexualidad. Corregidor.

Gimeno, M. (7 de marzo de 2018). Queridas viejas. Editando a Gombrich [Vídeo]. YouTube. youtube.com/watch?v=282sA83VJaU

Greer, G. (2005). La carrera de obstáculos. Vida y obra de las pintoras antes de 1950. Bercimuel.

Kuenzli, R. E. (1991). Surrealism and Misogyny. En M. A. Caws, R. E. Kuenzli y G. Raaberg (Eds.), Surrealism and Women (pp. 17-26). The MIT Press.

Mahon, A. (2009). Surrealismo, Eros y Política, 1938-1968. Alianza Editorial.

Mayayo, P. (2000). La novia frente a los solteros. Revista de libros, (45),8. revistadelibros.com/bachelors-de-rosalind-krauss/

Millet, K. (1995). Política sexual. Cátedra.

Sade, M. d. (1795). La filosofía en el tocador. Freeditorial. freeditorial.com/es/ books/filosofia-en-el-tocador/related-books 